\title{
Correction and Republication: Abortion Surveillance - United States, 2014
}

On November 24, 2017, MMWR published "Abortion Surveillance - United States, 2014" (1). On August 6, 2018, the authors informed MMWR about inadvertent errors in the data that resulted in publication of some erroneous numbers for gestational ages and abortion ratios throughout the report. The authors have corrected these errors and confirm that the interpretation or the conclusions of the original report have not changed. Additional text has been added to clarify how CDC adjusts gestational age data. In accordance with December 2017 guidance from the International Committee of Medical Journal Editors (2), MMWR is republishing the corrected report. The republished report has supplementary materials that include the original report with these corrections and additional text clearly marked (3).

\section{References}

1. Jatlaoui TC, Shah J, Mandel MG, et al. Abortion surveillance-United States, 2014. MMWR Surveill Summ 2017;66(No. SS-24). https://doi. org/10.15585/mmwr.ss6624a1

2. International Committee of Medical Journal Editors (ICMJE). Corrections, retractions, republications and version control. Vancouver, British Columbia: International Committee of Medical Journal Editors (ICMJE); 2017. http://www.icmje.org/recommendations/browse/ publishing-and-editorial-issues/corrections-and-version-control.html

3. Jatlaoui TC, Shah J, Mandel MG, et al. Abortion surveillance-United States, 2014. MMWR Surveill Summ 2018;66(No. SS-25). Corrected and republished from: MMWR Surveill Summ 2017;66(No. SS-24). https://doi.org/10.15585/mmwr.ss6625a1 